\title{
Fake news, desinformação e necessidade de formar leitores críticos
}

\author{
Eulália Leurquin* \\ Chloé Leurquin**
}

\begin{abstract}
Resumo
Este artigo apresenta uma discussão sobre fake news e desinformação, considerando efeitos desses fenômenos na sociedade contemporânea e atentando para a necessidade de formar leitores críticos, conscientes da exigência de conhecer a origem das informações. Nosso objetivo é mostrar como as fake news e a desinformação se originam, se constituem e propagam seus efeitos na sociedade. Os dados analisados estão situados em dois momentos importantes no país: o período das eleições a Presidente da República do Brasil, em 2018, e o segundo ano da pandemia decorrente da covid-19, em 2021. Analisamos o contexto de produção das fake news e da desinformação, considerando o contexto de produção, o mundo físico e o sociossubjetivo, bem como os mecanismos enunciativos (BRONCKART, 1999, 2019), buscando argumentar a favor da formação de leitores críticos (KLEIMAN; SANTOSMARQUES, 2020; LEURQUIN, 2001, 2014; LEURQUIN; LEURQUIN, 2021; BRASIL, 2017).
\end{abstract}

Palavras-chave: Fake news. Desinformação. Letramento. Formação de leitor.

\footnotetext{
* Professora do Departamento de Letras Vernácula, Universidade Federal do Ceará. ORCID: https://orcid.org/0000-0001-75321210.

** Doutoranda do Curso de Pós-graduação em Comunicação, Universidade Federal de Minas Gerais. ORCID: 0000-0002-11842655.
} 


\section{La désinformation et la necessite de former des lecteurs}

\section{Résumé}

Cet article présente une discussion sur les fake news et la désinformation, en considérant les effets de ces phénomènes dans la société contemporaine qui doit répondre à la nécessité de former des lecteurs critiques, conscients de l'exigence de connaître l'origine des informations. Notre objectif est celui de montrer l'origine des infox et de la désinformation, de savoir comment ils sont constitués et comment leurs effets se propagent dans la société. Les données analysées sont situées à deux moments importants du pays: la période des élections présidentielles de la République du Brésil en 2018; et la deuxième année de la pandémie due au covid-19, en 2021. Nous avons analysé le contexte de production des infox et de la désinformation, en considérant leur production, le monde physique et socio-subjectif, tout comme les mécanismes énonciatifs (BRONCKART, 1999, 2019). À partir de l'articulation que nous avons établie, ayant pour objectif la nécessité de former des lecteurs critiques SantosMarques (2020) et Leurquin (2001, 2014), Leurquin e Leurquin (2021) et Brasil (2017), nous avons également eu recours aux études sur le littérisme idéologique de Street, (2014).

Mots - clés: Fake news. Désinformation. Literaty. Formation de lecteur.

Recebido em: 15/07/2021 // Aceito em: 4/10/2021. 


\section{Introdução}

Decorrentes do avanço das tecnologias e do processo de midiatização da sociedade, as formas de interagir e de comunicar, a rapidez no processamento e na divulgação de informações, assim como suas reverberações na sociedade, parecem ganhar atualmente uma força antes inimaginável. Essas características da contemporaneidade atraem a atenção de grupos, muitas vezes políticos, que, movidos por interesses ideológicos, aproveitam para fazer circular fake news e desinformação, ${ }^{1}$ lançando inverdades para a população. Estudos divulgados em meios de comunicação de grande alcance e notoriedade, como a Folha de São Paulo² e o jornal O Globo, alertam para o fato de que fake news e desinformação atingem atualmente um número maior de leitores/ouvintes e que a rapidez no alcance dos seus objetivos é muito superior, comparada às notícias divulgadas pelos meios tradicionais de comunicação, conforme veremos mais adiante. Pesquisas na área de Comunicação (DOURADO; GOMES, 2019; SANTOS, 2020; FREITAS, 2020, entre outros) discutem o comportamento e uso da informação na era do digital e apresentam conclusões que nos mostram, com preocupação, a necessidade de evidenciar muito mais esse tema nos debates da área de Comunicação.

As fake news chamaram especial atenção e tiveram visibilidade mundial a partir do uso feito pela extrema direita, que resultou na interferência direta nos resultados do processo eleitoral americano de 2016, que elegeu Donald Trump, conforme afirma Berger (2019) no prefácio da obra Jornalismo, fake

1 Na sequência do artigo, mostraremos a nossa posição quanto à opção pelo termo "desinformação".

2 Sobre fake news no jornal Folha de São Paulo e jornal o Globo, ver em: https://m.folha.uol.com.br/folha-topicos/fakenews/?pg=2 e https://gl.globo.com/fato-ou-fake. 
news e Desinformação: manual para educação e treinamento e jornalismo, citando Becker e Goes. No Brasil, elas assumiram um espaço também de grandes proporções e contribuíram para eleger, em 2018, o atual presidente, Jair Messias Bolsonaro. Na Europa, o mesmo fenômeno aconteceu devido aos referendos realizados sobre a saída do Reino Unido da União Europeia.

Como reação aos desdobramentos das fake news e desinformação, em 2017, foi divulgada a Declaração Conjunta sobre Liberdade de Expressão e "Notícias Falsas" ("Fake News"), Desinformação e Propaganda, assinada pela Relatoria Especial das Nações Unidas (ONU) para Liberdade de Opinião e Expressão e pela Relatoria Especial da Organização dos Estados Americanos (OEA) para a Liberdade de Expressão. Entender o limite entre a liberdade de expressão, a notícia falsa e a desinformação ainda é um ponto a ser atingido.

A preocupação com o impacto das fake news e da desinformação na política e na vida social tem mobilizado esforços no Brasil, na Colômbia, nos Estados Unidos, na Índia, na França, na Nigéria e em muitos outros países. No Brasil, em 2020, Fake news e desinformação foram tema principal da publicação da cartilha Desinformação, ameaça ao direito à informação, muito além das fake news, ${ }^{3}$ de autoria do Coletivo Brasil de Comunicação (Intervozes).

Fato é que a expressão "fake news" ("notícia falsa") popularizou-se mundialmente e se tornou comum nas conversas cotidianas, em casa, no trabalho, no bar, na escola, na academia etc. Esse fenômeno, entretanto, não chamou a atenção apenas de pesquisadores da área de Comunicação já citados, mas também vem interessando cada vez mais pesquisadores da área de Linguística Aplicada, como por exemplo Kleiman e SantosMarques (2020), Leurquin (2001, 2014 2021).

3 Disponível em: https://boanoticia.org.br/lancamento-da-cartilha-desinformacao-ameaca-ao-direito-a-comunicacao-muitoalem-da-fake-news/ 
Este artigo, portanto, reúne reflexões desenvolvidas por uma jornalista e uma linguista aplicada e traz dois pensamentos que se complementam. Se, por um lado, discutimos o fenômeno das fake news e desinformação nas práticas sociais de linguagem, seus efeitos na política e suas reverberações na sociedade, por outro lado, contemplamos a formação de leitores críticos, pensando no espaço sala de aula de Língua Portuguesa, onde ensinamos como se constitui uma desinformação, sua circulação em forma de gênero de texto do campo de atuação na vida pública (BRASIL, 2017) e seus efeitos na formação de leitores críticos.

A reflexão que orienta nossa discussão tem como norte as seguintes perguntas a que, diretamente ou não, buscaremos responder neste artigo: Como desdobramentos da desinformação afetam na sociedade? Por que a atitude de curador diante da desinformação é importante no Brasil da contemporaneidade? Por que formar leitores críticos é uma atitude de resistência na sociedade atual? Como o fenômeno da desinformação afeta na discussão sobre a formação do leitor crítico? Para isso, elegemos como referência para nossas análises o discurso proferido pelo Presidente da República do Brasil Jair Messias Bolsonaro, no dia 2 de junho de 2021, e as desinformações divulgadas em redes sociais durante a sua campanha a Presidente da República, em 2018.

Inicialmente, situadas na discussão desenvolvida no seio da Comunicação, apresentamos uma discussão sobre fake news e desinformação, esclarecendo nossa opção pelo termo "desinformação"; depois, no âmbito da Linguística Aplicada, alinhadas às orientações da Base Nacional Comum Curricular (BRASIL, 2017), dos estudos do letramento ideológico(STREET, 2014), do interacionismo sociodiscursivo (BRONCKART, 
1999, 2019) e de discussões desenvolvidas sobre a formação de leitores críticos (KLEIMAN; SANTOS-MARQUES, 2019; LEURQUIN, 2001, 2014; LEURQUIN; LEURQUIN, 2021), analisamos a constituição, o uso e os efeitos da desinformação; por fim, assumimos a importância da curadoria no tratamento das informações trazidas no texto como uma opção necessária e, na sequência, apresentamos nossas considerações finais.

\section{Sobre Fake news, desinformação e formação de leitores críticos: três pontas que se unem}

O fenômeno de disseminar informações falsas ou de "maquiar" a realidade não é novidade e se tornou ainda mais perigoso devido à rapidez de sua propagação. $\mathrm{O}$ alcance e a repercussão que as redes sociais podem proporcionar vêm permitindo que essas práticas sociais ganhem um peso antes inimaginável. Esses fatores impulsionaram, no campo das comunicações, outra situação que é a deformação das informações dando origem às denominadas fake news e à desinformação.

$\mathrm{O}$ fato de os conteúdos divulgados pelos diferentes meios digitais terem alcance rápido e de grandes proporções, conforme já foi dito, traz como efeito dois desdobramentos que se unem em uma necessidade significativa e urgente de formar leitores críticos, considerado o contexto das atividades linguageiras contemporâneas. O primeiro desdobramento se representa como positivo, pois diz respeito à potencialidade que tem a divulgação por meio das mídias e seu alcance na sociedade; o segundo diz respeito à qualidade e à confiabilidade do conteúdo. Quando o leitor/ouvinte não procura a origem dos fatos para se certificar de sua veracidade e passa a informação adiante, provavelmente 
pela confiança nos meios de comunicação ou nas próprias pessoas que compartilham o conteúdo, os danos causados pelas postagens falsas ou com distorções podem ser irrevogáveis.

A discussão sobre as fake news está além de saber se o conteúdo é verdadeiro ou falso, o que já é muito sério. Freitas (2018), citando Lazer et al., apresenta fake news como "notícias fabricadas que imitam textos jornalísticos em sua forma, mas não em seu processo organizacional e na intenção [...]”. Para a autora, elas se comportam parasitando sites noticiosos, buscando enganar e ludibriar audiências, não sendo meros equívocos. Fato é que as fake news põem em risco a credibilidade do jornalismo como instituição e do jornalista como profissional. Elas são oriundas, principalmente, de gêneros de textos que circulam na esfera pública, nos campos jornalístico-midiático, ou dos gêneros de atuação na vida pública (BRASIL, 2017).

Em torno da discussão sobre a pós-verdade, fake news e desinformação ganham espaço. Para, por exemplo, discutir o conceito de fake news, a UNESCO lançou um manual, em que se lê:

[...] que o termo fake news ("notícias falsas") possua um significado direto ou comumente compreendido. Isso ocorre porque "notícias" significam informações verificáveis de interesse público, e as informações que não atendem a esses padrões não merecem o rótulo de notícias. Nesse sentido, então, a expressão "notícias falsas" é um oxímoro (que exprimem conceitos contrários) que se presta a danificar a credibilidade da informação que de fato atende ao limiar de verificabilidade e interesse público - isto é, notícias reais. (IRETON; POSETTI , 2019, p. 7, grifo dos autores). 
A publicação Desinformação, ameaça ao direito à comunicação, muito além de fake news (INTERVOZES, 2019) lembra-nos que a expressão "fake news" ("notícia falsa") se popularizou mundialmente e se tornou comum nas conversas cotidianas, em casa, no trabalho, no bar, na escola etc. Nela se aborda ainda que a preocupação com o impacto desse fenômeno na política e na vida social tem mobilizado esforços no Brasil, na Colômbia, nos Estados Unidos, na Índia, na França, na Nigéria e em diversos países, conforme podemos perceber. Também discutindo sobre fake news, França e Leurquin (2020, p. 292) defendem que "fake news é uma expressão que se consagrou recentemente para nomear a distorção de fatos e/ou criação de mentiras como arma política para combater adversários [...]”. Nesse mesmo trabalho, as autoras se posicionam pelo termo “desinformação", posição que aqui seguimos.

A escolha pelo termo "desinformação", ao tratar do fenômeno em questão, ocorre porque este se diferencia de fake news, que se sustenta na tentativa deliberada de confundir e manipular a sociedade. Não se trata simplesmente de uma "mentira inocente", mas de uma estratégia política que visa à disseminação de inverdades de forma planejada, sistêmica e articulada para fins específicos. Essa posição está alinhada ao posicionamento tomado no prefácio (BERGER, 2019 do Jornalismo, fake news e desinformação: manual para educação e treinamento em jornalismo. O mesmo manual defende que:

[...] o termo desinformação é comumente usado para se referir a tentativas deliberadas (frequentemente orquestradas) para confundir ou manipular pessoas por meio de transmissão de informações desonestas. Isso geralmente é combinado com estratégias de comunicação paralelas e cruzadas e um conjunto de outras táticas, como hackear, ou comprometer pessoas. (BERGER, 2019, p. 9). 
Entendendo que desinformação é um conceito que pode abranger as próprias fake news, ressaltamos dois momentos no Brasil, isto é, a campanha eleitoral para Presidente da República em 2018 e a pandemia decorrente da covid-19 nos anos 2020 e 2021, como base de nossas reflexões. Tendo em conta a defesa da formação de leitores críticos, precisamos atentar para todas as particularidades que cercam o fenômeno da desinformação, que pode circular em meios diversos de comunicação (rádio, televisão, entres outros), em distintos gênero de texto (postagem de Facebook, e-mail, pronunciamento político, aula etc.); pode também ser oral (palestra, entrevista, conferência, por exemplo), escrita (carta, bilhete, entre outros) e/ou multissemiótica.

\title{
3 Trazendo a discussão para o espaço da sala de aula
}

Desde os Parâmetros Curriculares Nacionais (PCN) (BRASIL, 1998), o texto passou a ser a centralidade do ensino/ aprendizagem da língua materna, e o gênero de texto assume o status de megainstrumento. Sobre o gênero de texto, os Parâmetros Curriculares Nacionais posicionam-se da seguinte forma:

\begin{abstract}
Todo texto se organiza dentro de determinado gênero em função das intenções comunicativas, como parte das condições de produção dos discursos, as quais geram usos sociais que os determinam. Os gêneros são, portanto, determinados historicamente, constituindo formas relativamente estáveis de enunciados, disponíveis na cultura. (BRASIL, 1998, p. 21).
\end{abstract}

Seguindo essas orientações, a Base Nacional Comum Curricular (BNCC) (BRASIL, 2017), apesar das muitas críticas 
que a ela precisamos fazer, avança na discussão sobre o papel dos gêneros de texto em sala de aula de língua materna e reforça a importância da abordagem descendente de análise de gêneros de textos, ao apresentar os campos de atuação (BRASIL, 2017). De acordo com a BNCC do ensino fundamental, anos finais, lugar de nossas reflexões sobre a formação de leitores críticos, o professor deve considerar os quatro campos de atuação (artístico-literário, campo de atuação na vida pública, práticas de estudos e pesquisas e jornalístico-midiático), espaços nos quais emerge o gênero textual. Por razões diferentes, a desinformação atinge mais os espaços do campo de atuação na vida pública e do campo de atuação jornalístico-midiático.

Ainda conforme os PCN e a BNCC, o processo de ensino e aprendizagem da língua materna deve acontecer de forma a contemplar uma dinâmica que compreenda reflexão e ação, e que sejam basilares as práticas de leitura/escuta, produção, análise linguística/semiótica e oralidade. No conjunto das quatro práticas de linguagem, destacamos aqui a leitura/escuta para pensar a formação de leitor crítico.

A BNCC apresenta dois fundamentos pedagógicos para o ensino e aprendizagem no nível do ensino fundamental. $\mathrm{O}$ primeiro fundamento é foco no desenvolvimento de competências e o segundo fundamento é o compromisso com a educação integral. Sobre o primeiro fundamento, o documento em quentão afirma que:

Ao adotar esse enfoque, a BNCC indica que as decisões pedagógicas devem estar orientadas para o desenvolvimento de competências. Pormeio daindicação clara do que os alunos devem "saber" (considerando a constituição de conhecimentos, habilidades, atitudes e valores) e, sobretudo, do que devem "saber fazer" (considerando a mobilização desses conhecimentos, 
habilidades, atitudes e valores para resolver demandas complexas da vida cotidiana, do pleno exercício da cidadania e do mundo do trabalho), a explicitação das competências oferece referências para o fortalecimento de ações que assegurem as aprendizagens essenciais definidas na BNCC. (BRASIL, 2017, p. 13).

Tal posicionamento está articulado ao conceito de competência, entendida como "a mobilização de conhecimentos (conceitos e procedimentos), habilidades (práticas, cognitivas e socioemocionais), atitudes e valores para resolver demandas complexas da vida cotidiana, do pleno exercício da cidadania e do mundo do trabalho [...]" (BRASIL, 2017, p. 8). Esse conceito ainda é bastante amplo e, por isso, não dá conta das especificidades do uso efetivo da língua nas práticas reais de comunicação. O segundo fundamento (compromisso com a educação integral), de certa forma, nos permite fortalecer a discussão sobre desinformação e, sobretudo, refletir sobre o papel da escola e o objetivo maior do ensino e aprendizagem da língua materna.

A prática de linguagem leitura/escuta está situada no eixo leitura, e nele podemos pensar a "interação ativa do leitor/ouvinte/ espectador com os textos escritos, orais e multissemióticos e de sua interpretação [...]" (BRASIL, 2017, p. 71) que acontece no encontro do leitor com o autor do texto. Essa interação acontece mediada pelo gênero textual, que, a depender do propósito de comunicação, tem uma composição diferente do dizer. Esse dizer é observado e analisado graças à sua semiotização no texto. Nesse contexto, o gênero de texto não apenas permite uma interação entre os envolvidos no processo da leitura, como também é um objeto de ensino e aprendizagem da língua portuguesa. 
Chamamos a atenção para o fato de que, quando o professor está no movimento da construção coletiva dos sentidos do texto, a concepção de leitura é ampliada e não estão em jogo apenas o leitor-aluno e o autor do texto, mas também o professor que é um leitor e um formador de leitores (LEURQUIN, 2001, 2014; LEURQUIN; LEURQUIN, 2021). O papel do professor como leitor e formador de leitores é fundamental para o bom resultado do ensino. Essas questões estão contempladas na BNCC, em suas orientações (BRASIL, 2017, p. 73-74) sobre o tratamento das práticas leitoras nos sete níveis orientacionais para as entradas no texto:

a) Reconstrução e reflexão sobre as condições de produção e recepção dos textos;

b) Dialogia e relação entre textos;

c) Reconstrução da textualidade, recuperação e análise da organização textual, da progressão temática e estabelecimento de relações entre as partes do texto;

d) Reflexão crítica sobre as temáticas tratadas e validade das informações;

e) Compreensão dos efeitos de sentido provocados pelos usos de recursos linguísticos e multissemióticos;

f) Estratégias e procedimentos de leitura;

g) Adesão às práticas de leitura.

Todos os níveis são fundamentais para a formação de um leitor crítico. As orientações sobre a leitura/escuta possibilitamnos, ainda, estabelecer uma relação entre texto e gramática. O documento evidencia elementos contextuais, situações de produção do texto lido e elementos que nos remetem ao 
plano discursivo. Acrescentamos, nesta reflexão, elementos relacionados às questões históricas e políticas, pois elas podem permitir compreender o fenômeno da desinformação numa perspectiva mais ampla e crítica.

Em se tratando dos níveis que orientam o estudo do texto, salientamos o nível "d", cujo propósito é investigar as origens do texto lido. Com base nessa orientação, o professor precisa, para desenvolver no leitor uma "Reflexão crítica sobre as temáticas tratadas e ter validade das informações [...]", além de contemplar as competências necessárias para fazer o leitor "Refletir criticamente sobre a fidedignidade das informações, as temáticas, os fatos, os acontecimentos, as questões controversas presentes nos textos lidos, posicionando-se [...]" (BRASIL, 2017, p. 73). Essa orientação é retomada em forma de habilidades a serem desenvolvidas na prática de linguagem leitura, tanto no $9^{\circ}$ ano, quanto no $8^{\circ}$, apresentando-se como a habilidade de número 01, conforme constatamos:

(EF08LP01) Identificar e comparar as várias editorias de jornais impressos e digitais e de sites noticiosos, de forma a refletir sobre os tipos de fato que são noticiados e comentados, as escolhas sobre o que noticiar e o que não noticiar e o destaque/enfoque dado e a fidedignidade da informação. (grifo nosso).

(EF09LP01) Analisar o fenômeno da disseminação de notícias falsas nas redes sociais e desenvolver estratégias para reconhecê-las, a partir da verificação/ avaliação do veículo, fonte, data e local da publicação, autoria, URL, da análise da formatação, da comparação de diferentes fontes, da consulta a sites de curadoria que atestam a fidedignidade do relato dos fatos e denunciam boatos etc. (BRASIL, 2017, p. 175 grifo nosso). 
Ao considerar as duas habilidades, percebemos uma certa progressão na prática de leitura/escuta. No $8^{\circ}$ ano, observamos que o foco está relacionado à ação de identificar os editoriais, perceber as diferenças entre eles e também se atentar para a fidedignidade da informação. Essas características e procedimentos apresentam-se como basilares para o trabalho de curadoria e também para a formação do leitor crítico que defendemos aqui. No $9^{\circ}$, o leitor já deve estar atento para certificar-se da fidedignidade da informação. Essa habilidade apresenta estratégias que facilitam a atividade de curadoria.

Tendo em conta a discussão que fizemos sobre as desinformações que, de forma acelerada, se propagam devido à rapidez do processamento e à divulgação de informações, e considerando diretrizes para a formação do leitor crítico, conforme pautam orientações da BNCC, no esforço de contribuir para a discussão sobre o papel da educação no combate à desinformação, passamos, na sequência, a abordar exemplos em que se materializa o fenômeno da desinformação, selecionados a partir de dois recortes temporais: as eleições para presidente no Brasil (em 2018) e a pandemia de covid-19 (2020-2021). Para isso, articularemos contribuições construídas nos campos da Comunicação e da Linguística Aplicada.

\section{4 o curador e a desinformação na sociedade contemporânea: uma relação necessária de resistência na formação de leitores críticos}

O papel de curador é muito importante, pois ele nos permite ter acesso à informação original e desvendar a construção 
e disseminação da desinformação. Esse trabalho exige uma pesquisa criteriosa para ter acesso às fontes da desinformação e daí iniciar um outro trabalho, que é de interpretação da desinformação. No Brasil, a Agência Lupa tem grande destaque no trabalho de desvendar as principais notícias na internet. Dentre muitos resultados publicados por essa agência, destacamos, inicialmente, o levantamento feito sobre desinformações divulgadas pelo atual Presidente da República do Brasil, Jair Bolsonaro, em seu discurso proferido, em cadeia nacional, no dia 2 de junho de 2021, para tratar da pandemia da covid-19.

$\mathrm{O}$ resultado desse trabalho levado a efeitos pela Agência Lupa está divulgado sob o título "Em pronunciamento, Bolsonaro distorce dados de vacinação no país e erra sobre BR163" (MACÁRIO et. al. 2021). Vejamos:

\section{Quadro I - Discurso}

\section{DISCURSO}

"Em pronunciamento na noite desta quarta feira, o presidente da República, Jair Bolsonaro, voltou a falar sobre ações do governo durante a pandemia de covid-19, como o desenvolvimento e distribuição de vacinas, o auxílioemergencial e a destinação de recursos a estados e municípios. Também falou sobre medidas aprovadas pelo Congresso Nacional e sobre realizações de seu governo na área de infraestrutura. A Lupa checou algumas das frases ditas pelo presidente. O Palácio do Planalto foi procurado para comentar, mas não respondeu até a publicação da checagem".

"Hoje, alcançamos a marca de 100 milhões de doses de vacinas distribuídas a estados e municípios"

Jair Bolsonaro (sem partido), presidente da República, em pronunciamento na TV no dia 2 de junho de 2021 


\section{VERDADEIRO}

Até 2 de junho, o Ministério da Saúde distribuiu 102.915.464 doses de vacinas para os estados. Nem todas essas doses já foram aplicadas. De acordo com informações do Locliza SUS, que reúne dados sobre a campanha de imunização contra a Covid no país, 68,9 milhões de doses foram aplicadas, sendo que 46,4 milhões correspondem à primeira dose. No total, 22,4 milhões de pessoas já foram vacinadas com as duas doses.

\section{DISCURSO}

"O Brasil é o quarto país que mais vacina no planeta"

Jair Bolsonaro (sem partido), presidente da República, em pronunciamento na TV no dia 2 de junho de 2021

\section{VERDADEIRO, MAS}

O Brasil é o quarto país do mundo em número de pessoas que receberam ao menos uma dose de vacina contra a covid-19. Mas isso não quer dizer que $o$ Brasil tenha a quarta melhor cobertura vacinal do mundo, já que é também um dos países mais populosos do planeta. Levando-se em consideração o número de pessoas vacinadas em relação à população total, o Brasil cai dezenas de posições no ranking de imunização.

\section{DISCURSO}

"Ontem assinamos acordo de transferência de tecnologia para produção de vacinas no Brasil entre a AstraZeneca e a FioCruz (...)" Jair Bolsonaro (sem partido), presidente da República, em pronunciamento na TV no dia 2 de junho de 2021

\section{VERDADEIRO}

$\mathrm{Na}$ última terça-feira $\left(1^{\circ}\right)$, a Fundação Oswaldo Crus (Fiocruz) assinou um acordo com a farmacêutica AstraZeneca para a transferência de tecnologia para a produção do Ingrediente Farmacêutico Ativo (IFA), insumo utilizado para a produção de vacinas contra a covid-19. Assim, a instituição conseguirá produzir um imunizante contra o novo coronavírus sem depender da importação do IFA. 
$\mathrm{O}$ processo de transferência de tecnologia está em andamento. Nesta quarta-feira (2), a Fiocruz recebeu materiais para a produção do IFA, e a equipe segue sendo treinada para realizar o trabalho. A previsão, segundo a Fiocruz, é de que as entregas comecem apenas em outubro.

\section{“(...) Com isso [produção de IFA pela Fiocruz], passamos a integrar} a elite de apenas cinco países que produzem vacina contra o Covid no mundo"

Jair Bolsonaro (sem partido), presidente da República, em pronunciamento na TV, no dia 2 de junho de 2021

\section{FALSO}

Não são apenas quatro países que produzem, atualmente, vacinas contra covid-19. Segundo a Unicef, atualmente, 37 países produzem vacinas localmente contra a doença, entre eles, o Brasil.

O que a Fiocruz anunciou é que conseguirá produzir o IFA da vacina AstraZeneca no país, ou seja, o Brasil não dependerá da importação desses insumos para produzir esse imunizante, especificamente. Segundo reportagem do Jornal o Estado de S. Paulo, apenas Rússia, China, Índia e Estados Unidos, atualmente, são autossuficientes na produção da vacina.

Além disso, a produção do IFA e da vacina 100\% nacional não começará imediatamente. Segundo a própria Fiocruz, a expectativa é que isso ocorra somente em outubro. Até lá, o

Brasil seguirá dependente da importação de IFAs para a produção de imunizantes. A capacidade de produção mensal será de 15 milhões de doses por mês, segundo a instituição.

Fonte: Agência Lupa, 2021

Conforme já dissemos, a desinformação pode circular em qualquer espaço de comunicação, em um texto oral, escrito ou multisemiótico. A sua circulação pode se dar por qualquer meio de comunicação, em qualquer formato de gênero de texto. Uma característica é a intenção de prejudicar, de desinformar, de confundir o leitor/ouvinte, mas também pode-se assumir 
que o objetivo maior seja beneficiar alguém, um grupo ou um projeto de poder. O propósito forte é que elas circulem muito rapidamente com o objetivo de alcançar um número muito grande de leitores/ouvintes. Elas podem ser motivadas por questões sociais, políticas, econômicas, sanitárias etc.

Tomemos o exemplo trazido, a partir das contribuições do Interacionismo sociodiscursivo, que nos leva a considerar o contexto de produção, os mundos representados e o nível da coerência interativa assegurado pelos mecanismos enunciativos (BRONCKART, 1999, 2019). O contexto de produção - “o conjunto de parâmetros susceptíveis de exercer uma influência sobre a maneira que o texto é organizado [...]" (BRONCKART, 1999, p. 35) - carrega elementos do mundo físico e do mundo sociosubjetivo que implicam papéis que o produtor do texto assume, o modo como ele se representa no mundo e o nível de coerência responsável pelas modalizações utilizadas e pelas vozes assumidas no texto, mostrando posicionamentos assumidos. Coerente com essa opção teórico-metodológica, aproximamo-nos dos estudos do letramento, considerada sua condição ideológica, conforme Street (2014), e das discussões sobre a formação do leitor crítico (KLEIMAN; SANTOSMARQUES, 2020), porque também entendemos que todas as práticas de letramento envolvem aspectos não apenas culturais, mas também fatores de poder na sociedade. Esse poder, na discussão ora desenvolvida, está vinculado ao papel assumido pelos envolvidos na divulgação da desinformação e é fortemente motivado pelas intenções que motivam as relações sociais e políticas em torno da saúde, segurança e educação do país.

Ao destacar o contexto de produção em que ocorreu o discurso do presidente no exemplo trazido, lembramos que, 
desde o início da pandemia, o Ministério da Saúde do Brasil não apresentou um plano para o combate à pandemia que envolvesse estados e município, exercendo a sua função de coordenador geral das políticas públicas na área de saúde no país. Pelo contrário, em pouco mais de um ano, o país chegou a seu quarto ministro da saúde, conforme podemos constatar. De $1^{\circ}$ de janeiro de 2019 a 16 de abril de 2020, o Brasil tinha como ministro Luiz Henrique Mandetta. Por menos de um mês (17 de abril de 2020 a 15 de maio do mesmo ano), Nelson Teich assumiu o Ministério da Saúde. Durante quase vinte dias (15 de maio de 2020 a 2 de junho de 2020), o Brasil ficou sem ministro da saúde, quando a pandemia estava em um dos momentos mais críticos. Eduardo Pazuello assumiu interinamente o cargo em 15 de maio e oficialmente permaneceu de 2 de junho de 2020 a 23 de março de 2021. Marcello Queiroga assumiu o cargo em 23 de março de 2021.

A não implementação de políticas públicas, visando ao controle da pandemia, levou o governo federal à percentagem recorde de 53,8\% de desaprovação, de acordo com pesquisas realizadas pelo instituto de pesquisas Paraná Pesquisas e publicadas na revista Veja de 20 de junho de $2021 .{ }^{4}$ A constituição brasileira confere aos três entes federativos, União, estados e municípios, a responsabilidade pela implementação de políticas públicas na área de saúde, sob a coordenação do Ministério da Saúde. No entanto, com a recusa do Ministério em assumir essa coordenação, esse assunto foi judicializado e o Supremo Tribunal Federal determinou que estados e municípios têm autonomia para implementar as políticas públicas, o que não exclui a União de suas responsabilidades constitucionais.

4 Cf em https://veja.abril.com.br/blog/maquiavel/desaprovacao-ao-governo-jair-bolsonaro-e-a-maior-em-mais-de-um-ano/ 
Um exemplo muito claro dessa situação é o da compra das vacinas que deveria ter sido realizada pelo Ministério da Saúde. No entanto, na ausência de coordenação da União, os governadores nordestinos fizeram o denominado Consócio Nordeste e adquiriram vacinas contra a covid-19, bem como articularam ações coordenadas de combate ao vírus. Essa ausência de gerenciamento por parte da União levou ao prolongamento da pandemia e a um elevado índice de mortes (mais de quinhentas e trinta mil) e de pessoas infectadas (mais de dezessete milhões e duzentos mil). ${ }^{5}$

Nesse contexto pandêmico, quando mais precisamos da credibilidade de nossas pesquisas, a ciência tem sido alvo de um discurso negacionista. Nesse panorama, perguntamos: Que voz o presidente assume ao falar com os brasileiros sobre esse tema? Como ele se representa e representa a nação em seu discurso? $\mathrm{O}$ presidente assume a voz social, aqui entendida como uma voz que provém de personagens, grupos ou instituições sociais que não intervêm como agentes no percurso temático, mas que são mencionados como instâncias externas de avaliação de alguns aspectos desse conteúdo (BRONCKART, 1999). Trata-se de um presidente que fala para o povo brasileiro. Dois fatores são essenciais nas desinformações que ele propaga em seu pronunciamento: primeiro, ele tem consciência do espaço e papel social que assume em seu discurso; ele conhece o grupo social para quem está falando. Então, alinha-se, de maneira complementar, a um discurso, aparentemente, de proteção para o povo brasileiro ("Hoje, alcançamos a marca de 100 milhões de doses de vacinas distribuídas a estados e municípios”) e de supervalorização do país (“O Brasil é o quarto país que mais

5 Informações de 11 de julho de 2021 (ver referências ao final do artigo). 
vacina no planeta"; "Com isso [produção de IFA pela Fiocruz], passamos a integrar a elite de apenas cinco países que produzem vacina contra o Covid no mundo [...]").

No primeiro excerto analisado pela Agência Lupa, há três elementos importantes da informação que o presidente Jair Bolsonaro quer divulgar. Primeiro, ele utiliza um recurso temporal (o advérbio de tempo "Hoje") como forma de mostrar para seu leitor/ouvinte uma espécie de agilidade em suas ações, de compromisso com o povo, ao situar a sua ação no presente. O segundo aspecto diz respeito à sua implicação no discurso, no dito "nós". Isso acontece por meio do uso da primeira pessoa flexionada no plural ("alcançamos"), mostrando que não apenas está implicado no que diz, como também traz o leitor/ouvinte para o seu discurso. Outro aspecto que merece ser observado é a opção por marcar a quantidade significativa de doses de vacinas distribuídas ("100 milhões"). Por fim, ele informa que a distribuição será feita tanto aos prefeitos quanto aos governadores. Essas informações têm um efeito particular sobre o leitor, quando consideramos o número alto de mortes e todo o movimento político que fizeram os governadores para negociar a venda das vacinas.

No segundo excerto, o presidente Bolsonaro utiliza a estratégia de valorizar o país. Para isso, ele utiliza a modalização apreciativa "mais", seguida da referência de lugar ("no planeta"), ao querer comparar a evolução do Brasil com relação a outros países, no enfrentamento da pandemia. Nisso, ele categoriza o Brasil como um dos países que mais vacina e depois estabelece relações com o planeta e não com outros países ou continentes.

No terceiro excerto ("Com isso [produção de IFA pela Fiocruz], passamos a integrar a elite de apenas cinco países que 
produzem vacina contra o Covid no mundo [...]"), destacamos que ele insere o Brasil em um lugar em que se encontra uma elite, como uma forma de valorização. Para isso, recorre à construção "passamos a integrar", depois, coloca o Brasil no quinto lugar na lista dos países que produzem vacina contra a covid-19. Usa o modalizador "apenas", de maneira positiva, para valorizar o país governado por ele. O presidente continua implicado em seu discurso, da mesma forma, utilizando a primeira pessoa do plural ("nós"). Ao observarmos a origem das informações, constatamos que são fundamentadas em argumentos construídos por meias verdades, de acordo com as análises realizadas pela Agência Lupa.

Como constatamos, parece haver um forte interesse em confundir a população. A estratégia discursiva se torna mais evidente, quando o presidente, que é a maior autoridade do país, dá informações verdadeiras, seguidas de meias verdades, entremeadas de informações completamente falsas, como mostram os jornalistas responsáveis pela publicação sob análise. Percebemos exatamente uma gradação em seu discurso no nível de veracidade das informações a que recorre. $\mathrm{O}$ contexto de produção do discurso, o fato de ele assumir o papel de Presidente da República pode contribuir para o nível de credibilidade do seu leitor/ouvinte. Isso fortalece a propagação da desinformação. Caberia, nesse caso, ao leitor/ouvinte usar de seus saberes para procurar a origem das informações.

A estratégia de divulgar desinformação envolve o contexto social, histórico e político. Cinco desinformações se destacaram nas últimas eleições presidenciais do Brasil. Elas são apresentadas no Blog de Marcello Patriota ${ }^{6}$, Trajano ${ }^{7}$ e no Diário

\footnotetext{
6 http://blogdomarcellopatriota.com.br/blog/?p=43628

7 http://www.ultrajano.com.br/cinco-fake-news-que-beneficiaram-a-candidatura-de-bolsonaro/
} 
da Amazônia ${ }^{8}$, são as seguintes ${ }^{9}$.

1 - O "kit gay" para crianças de 6 anos que foi distribuído nas escolas

2 - O homem que apunhalou Bolsonaro é filiado ao PT e aparece numa foto com Lula

3 - A senhora agredida por ser eleitora de Bolsonaro (que na verdade era Beatriz Segall).

4 - Haddad defende o incesto e o comunismo em um de seus livros

5 - Se Haddad chegar ao poder, pretende legalizar a pedofilia

Todos eles são construídos com imagens que complementam a desinformação e facilitam a compreensão do texto, além de chamar a atenção para a leitura. A rapidez com a qual disseminaram a desinformação é completamente desproporcional com o tempo utilizado para desfazer os danos causados; até hoje há quem acredite nessa desinformação. Com relação ao Partido dos Trabalhadores (PT), três pontos foram alvos para desqualificá-lo: agressividade (ataque a uma idosa e ao presidente); sexualidade na infância/família (kit gay e pedofilia) e família/religião (incesto). Sobre o tema agressividade, há desinformação que mostra o agressor de Bolsonaro ${ }^{10}$ sendo apontado como uma pessoa filiada ao PT. Após os resultados das eleições, foi comprovado que não havia ninguém com esse nome filiado ao partido, e a foto original mostrou ter passado por manipulações. Na imagem, há o ex-presidente Lula no centro

\footnotetext{
8 https://www.diariodaamazonia.com.br/cinco-fake-news-que-beneficiaram-a-candidatura-de-bolsonaro/

9 As duas referências nos remetem a uma manchete, Cinco 'fake news' que beneficiaram a candidatura de Bolsonaro, publicada no dia 19 de outubro de 2018 , pelo El País, às 17 h33min, atualmente indisponível.

10 No dia 6 de setembro de 2018, em um comício que promovia a sua campanha eleitoral, o deputado federal Jair Bolsonaro sofreu um atentado. O seu agressor foi identificado como Adélio Bispo de Oliveira.
} 
de uma multidão e o rosto do agressor muito próximo. Para a construção da outra desinformação, foi utilizada a fotografia da atriz brasileira Beatriz Segall. Apesar de a artista ser conhecida e de ter falecido cinco anos antes da divulgação da postagem, a desinformação ainda conseguiu se disseminar e seus objetivos foram alcançados.

\section{Imagem 1}
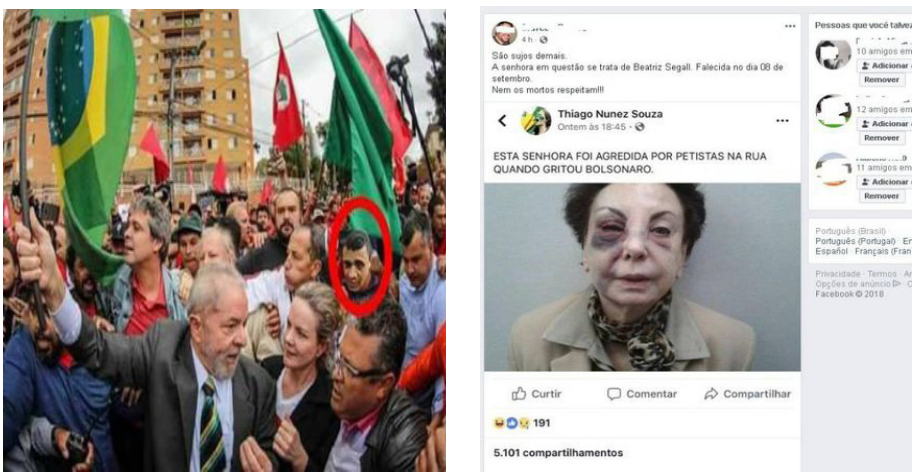

Fonte: Diário do Amazônia

Sobre o tema sexualidade na infância/família, há dois cartazes: um, com uma fotografia do candidato do PT e uma apelação: "Se você defende a criança, não vote nele. Haddad é o criador do kit gay para criança de 6 anos [...]". A ideia surgiu do projeto Escola Sem Homofobia, apresentado pelo então Ministro da Educação Fernando Haddad, em 2011. O objetivo era formar o professor para lidar com os direitos LGTB, no universo de jovens e adolescentes, de forma a respeitar a diversidade e não "sexualizar as crianças" ou "ensinar a ideologia de gênero na escola". O outro cartaz apresenta a imagem de uma criança com expressão de medo e proibida de falar, pela mão de um homem. No plano superior, há o número treze, que corresponde à identificação do PT nas eleições, o nome Lula e Haddad. Em seguida, aparece: "Torna a pedofilia um ato legal. O sexo com 
criança a partir de 12 anos deixaria de ser crime. Acha que essa merda é mentira, pesquise retardado. Projeto lei. PL 236 2012”. $\mathrm{Na}$ verdade, trata-se do projeto de lei do Senado 236/212, que propõe uma possível redução da idade de consentimento sexual de 14 para 12 anos. Fernando Haddad não esteve vinculado à sua tramitação, já que nunca ocupou um cargo legislativo. Foi apresentado pelo senador centro-direitista José Sarney (PMDBAP).

\section{Imagem 2}
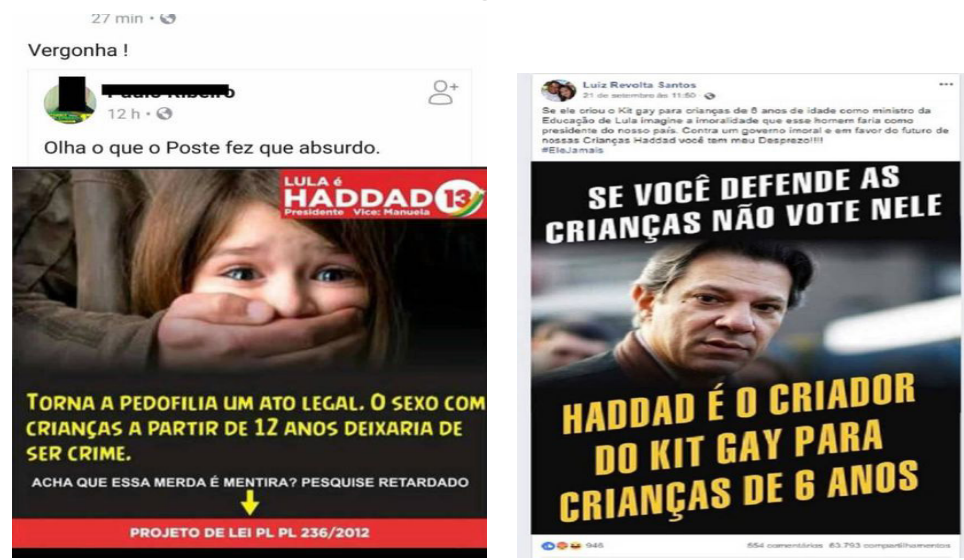

Fonte: Diário do Amazônia

O último cartaz selecionado para essa discussão apresenta o tema família/religião (incesto) e foi publicado em uma postagem sobre um livro de autoria de Haddad. Quando, como nesse caso, a desinformação decorre de uma figura conhecida ${ }^{11}$ com papel social muito bem definido e com credibilidade para um determinado grupo social, é muito mais rápida a disseminação e muito mais difícil de desmentir, mesmo quando deixe dúvidas quanto à origem dos fatos.

11 Olavo Luiz Pimentel de Carvalho é um professor, ensaísta brasileiro, influenciador digital, ideólogo. Foi jornalista e astrólogo. Autoproclamado filósofo, é considerado um representante do conservadorismo no Brasil. 


\section{Imagem 3}

\section{Olavo de Carvalho}

10 de outubro às 17:39

Na aula de sábado, explicarei direitinho a adesão do Haddad à apologia do incesto. A nota que retirei de circulaçăo dava a impressão de que isso constava do próprio livro dele, mas na verdade é uma idéia do Max Horkheimer à qual ele aderiu um tanto disfarçadamente.

Fonte: Diário do Amazônia

O professor Olavo de Carvalho dirige-se a seus pares para informar o tema de sua aula ("incesto"). Na construção da desinformação, dois pontos merecem ser destacados: a forma como ele estabelece relações entre o tema de sua aula e Fernando Haddad e a forma como ele destaca posições teóricas assumidas por Haddad. Inicialmente, utiliza um tom de provocação ("explicarei direitinho"), relacionando o referido tema ao candidato a Presidente da República do Brasil, nas eleições de 2018. Nesse momento, Olavo de Carvalho apresenta a primeira desinformação que, diretamente, pode afetar a pessoa de Fernando Haddad. Mais adiante, introduz a segunda desinformação, tentando desqualificar o candidato a presidência da república do Brasil com relação a posicionamentos feitos, no caso, sobre o sociólogo e filósofo Max Horkheimer. ${ }^{12}$ Também em relação ao livro de Haddad, Olavo de Carvalho informa ao

12 Filósofo e sociólogo alemão, autor da teoria crítica da sociedade e membro da "Escola de Frankfurt" de pesquisa social. 
seu público sobre a retirada de uma nota - aparentemente, mais uma inverdade, uma desinformação. Ainda sobre essa questão, introduz a adversativa "mas" e reforça com a afirmação "na verdade", chamando a atenção do seu leitor, para alcançar o seu objetivo que é desqualificar o candidato a presidente Fernando Haddad. Neste último caso, põe em jogo posicionamentos do político. A desinformação sobre o livro de Haddad foi analisada e está disponível no Estadão ${ }^{13}$ e no G1 Globo. ${ }^{14}$

Os cinco exemplos fornecidos pelo Blog Marcello Patriota, por Trajano e pelo Diário do Amazônia, a partir do El País, mostraram que há, de fato, uma seleção de temas para a construção da desinformação. Em um contexto de decisão de um processo de eleição, por exemplo, o que mais incomodava os eleitores passou a ser a referência temática para o ataque.

Consideramos que o fenômeno da desinformação abriu um espaço de discussão até então não corrente no contexto da sala de aula de leitura, referentemente à originalidade do texto. Atualmente, ao professor não basta apenas selecionar um texto para desenvolver a aula de leitura; é preciso que ele leve em conta fatores de desinformação ao fazer essa seleção.

\section{Considerações finais}

A desinformação tem efeitos graves na construção da cidadania e exige repensar a formação de leitores críticos, porque os parâmetros não são os mesmos. Ela é um fenômeno de interesse do pesquisador que estuda a linguagem nos diversos

13 https://politica.estadao.com.br/blogs/estadao-verifica/e-falso-que-haddad-defende-incesto-em-livro-publicado-em-1998/

14 https://g1.globo.com/fato-ou-fake/noticia/2018/10/16/e-fake-que-livro-escrito-por-haddad-incentive-o-incesto-e-cite-dezmandatos-do-comunismo.ghtml 
contextos de uso. Em especial, é de interesse para as áreas de Comunicação e da Linguística Aplicada, em particular, neste caso, quando se trata da formação de leitores críticos. Refletir sobre esse fenômeno a partir de dois olhares complementares nos exigiu fazer um distanciamento necessário do nosso objeto de estudo para pensarmos de maneira mais abrangente sobre ele.

Foi também com o olhar da Comunicação que pudemos pensar o texto fora da sala de aula com mais propriedade; trazer para a discussão a diferença entre fake news e desinformação, articulando as teorias do texto para pensar o trabalho do profissional em jornalismo, por exemplo, para trazer à tona a problemática contemporânea da confiabilidade da informação.

A desinformação e a manipulação de fatos e opiniões precisam ser tema da aula de leitura se realmente queremos formar um leitor crítico. Para isso, precisamos avançar na perspectiva de gerar dispositivos didáticos que possam contribuir para que o professor realize um trabalho de curadoria com seus alunos de maneira mais produtiva.

\section{Referências}

BERGER, Guy, Prefácio in IRETON, Cherilyn; POSETTI, Julie. Jornalismo, Fake News \& Desinformação: Manual para Educação e Treinamento em Jornalismo. UNESCO, 2019. 130 p. Disponível em: https://unesdoc.unesco.org/ark:/48223/ pf0000368647.

BRASIL, Secretaria de Educação Fundamental. Parâmetros curriculares nacionais: terceiro e quarto ciclos do ensino fundamental: língua portuguesa/Secretaria de Educação Fundamental. Brasília: MEC/SEF, 1998.106p. 
BRASIL. Base Nacional Comum Curricular. Educação é a base. Brasília, MEC/CONSED/UNDIME, 2017. Disponível em: http://basenacionalcomum.mec.gov.br/images/BNCC_EI_ EF_110518_versaofinal_site.pdf. Acesso em: 20 de set. 2021.

BRONCKART, Jean-Paul. Atividade de linguagem, textos e discursos: por um interacionismo

sociodiscursivo. Tradução de Anna Rachel Machado. São Paulo: Educ, 1999.

BRONCKART, Jean-Paul, Théories du langage: nouvelle introduction critique. Mardaga superieur: Bruxelle (Belgique), 2019.

DOURADO, Tatiana; Wilson GOMES. O que são, afinal, fake news, enquanto fenômeno de comunicação política? Brasília. Compolítica8, Associação Brasileira de Pesquisadores em Comunicação e Política. FAC Universidade de Brasília, v. 1, n. 1, p. 56, maio 2019

FRANÇA, Vera; LEURQUIN, Chloé. Diário da quarentena: a pandemia de COVID-19 como acontecimento. In: FRANÇA, Vera et al. Diário da quarentena. Belo Horizonte, MG: Fafich/ Selo PPGCOM/UFMG, 2020. 492 p. (Olhares Transversais, v. 2). Disponível em: https://seloppgcom.fafich.ufmg.br/novo/ publicacao/diario-da-quarentena. Acesso em: 7 out. 2021.

FREITAS, Viviane Gonçalves. O duplo aniquilamento de Marielle Franco: fake news como estratégia para liquidar o inimigo, Revista Mediação, Belo Horizonte, Minas Gerais, v. 22, n. 30, p. 23-41, jan-jun. 2020.

INTERVOZES. Desinformação, ameaça ao direito à comunicação, muito além de fake news. 2019. Disponível em: https://intervozes.org.br/publicacoes/desinformacao-ameacaao-direito-a-comunicacao-muito-alem-das-fake-news. Acesso em: 23 set. 2021. 
IRETON, Cherilyn; POSETTI, Julie. Journalism, 'Fake News' \& Disinformation: Handbook for Journalism Education and Training. UNESCO, 2019. 129 p.

IRETON, Cherilyn; POSETTI, Julie. Jornalismo, Fake News \& Desinformação: Manual para Educação e Treinamento em Jornalismo. UNESCO, 2019. 130 p. Disponível em: https:// unesdoc.unesco.org/ark:/48223/pf0000368647.

KLEIMAN, Ângela B.; SANTOS-MARQUES, Ivoneide Bezerra Araújo. Letramento crítico em contexto de crise: o papel da escola na era de pós-verdade e de crise In: KERSCHE, Dorotea Franck. Letramento na para a e além da escola. Campinas, São Paulo: Pontes, 2020. p. 29-56.

KLEIMAN, Ângela. B. Letramento e suas implicações para o ensino de língua materna. Signo, Santa Cruz do Sul, v. 32, n 53, p. 1-25, dez, 2007.

LEURQUIN, Eulália Vera Lúcia Fraga; LEURQUIN, Chloé Catarina Fraga. A segunda execução de Marielle: uma análise das fake news, In: CONGRESSO INTERNACIONAL DE LETRAS, 4., 2021, Bacabal. Anais [...]. UFMA. Bacabal. Maranhão. EDUFMA, 2021. p. 2126-2140.

LEURQUIN, Eulália Vera Lúcia Fraga. O espaço da leitura e da escrita em situação de ensino e de aprendizagem de português língua estrangeira. Eutomia Revista de Literatura e Linguística, Recife: Edições UFPE, v. 14, n. 1, p. 167-186, dez. 2014.

LEURQUIN, Eulália Vera Lúcia Fraga. O contrato de comunicação e concepções de leitura na prática pedagógica de língua portuguesa. 2001. Tese (Doutorado) - Universidade Federal do Rio Grande do Norte, Departamento de Educação, 2001.

MACÁRIO, Carol et al. Em pronunciamento, Bolsonaro distorce dados de vacinação no país e erra sobre BR-163. Revista Piauí, Rio de Janeiro: lupa@lupa.news, 2 jun.2021, Lupa. Disponível 
em: https://piaui.folha.uol.com.br/lupa/2021/06/02/bolsonaropronunciamento-covid-19. Acesso em: 7 out 2021.

SANTOS, Nina Fake news e mundos de Pós-verdade: que democracia em jogo? Revista Compolítica, Brasília: FAC Universidade de Brasília, v. 10, n. 3, mai. 2020. compolitica. org/revista ISSN: 2236-4781 DOI: 10.21878/compolitica. 2020.10.3.424. Disponível em www.compolítica.org 15 a 17 de maio. Brasília.

STREET, Brian V. Letramentos sociais: abordagens críticas do letramento no desenvolvimento, na etnografia e na educação. Tradução de Marcos Bagno. São Paulo: Parábola, 2014. 